\title{
BIOQ-BYWORD
}

\section{Reliability and Validity Research on the Reading Part in TEM-8 (2016-2021)}

\author{
Liqiao Liang* \\ *Corresponding author: Liqiao Liang, 68560948@qq.com
}

Graduate Institute of Interpretation and Translation, Shanghai International Studies University, Shanghai 200083, China

\begin{abstract}
TEM-8 is one of the most important exams for higher education (English major) students in China. By collecting and analyzing relevant reliability and validity data of recent TEM-8 (2016 to 2021), the reliability and validity of the examination (reading part) can be understood. This article discusses the exam's developing trend and provides suggestions for language teachers as well as exam candidates.
\end{abstract}

Keywords: TEM-8 reading part; Reliability; Validity; Teaching (studying) strategies; Higher education

Publication date: September 2021; Online publication: September 30, 2021

\section{Introduction}

The Test for English Majors Band 8 (TEM-8) is one of the most authoritative English language exams in China and it is a nightmare for many students. By typing “专八” or “TEM- 8 " in the largest Chinese search engine, Baidu, more than 100 million results can be found; however, most of them are commercials, which sell products to students ${ }^{[1]}$. This demarcates the exam's authority, difficulty, and value among students. Therefore, it is necessary to analyze its features in an overall view or its specific feature(s), which may be helpful for exam candidates and even possibly inspire those who design such exams.

The aim of this essay is, therefore, by evaluating the reliability and validity of the reading part in TEM8 in the last 6 years (2016 to 2021) with multiple approaches and comparing the results with the data from previous years that were collected by other researchers. In this way, the development trend of the exam's reading part can be revealed and both teachers as well as students can benefit from it.

\section{Literature review}

\subsection{TEM-8 and its evolution}

The syllabus of TEM-8, that had been initiated by the Chinese Ministry of Education in the year 1991 [2], had several revisions, where the two revisions in 2004 and 2016 were considered crucial ${ }^{[3]}$. The revision in 2016 led to significant changes in its examination methods.

\subsection{Previous research on the reading part in TEM-8}

Since TEM-8 is an authoritative exam for Chinese English majors, the research materials that had been referenced is from cnki.net, the most trusted Chinese scientific online research platform.

By typing the keyword “专业八级阅读” or “专八阅读” (“TEM-8 Reading Comprehension”), no significant works could be found. However, by typing "TEM-8 阅读理解” (“TEM-8 Reading Comprehension"), 44 works were found, of which the earliest ones could be traced back to the year of 2004. The latest TEM- 8 that researchers looked into was of the year 2018 and validity research was one of the 
most-adopted strategies. They offered suggestions either to reform the exam itself or for instructors' teaching methods and students' preparation.

Interestingly, most authors did not have the experience of participating in the setting of the exam. It is important to carry out diachronic research especially in this field. Although most researchers did not participate in the research and development of this exam, the reason they participated in this field is the hope that the performance of students sitting for the exam can be improved by revealing some characteristics of the exam's reading part.

\section{Methodology}

Analytical and statistical methods were mainly adopted in this research.

By deploying analytical methods, the reliability of the exam's reading part was examined on the basis of former scholars, and by implementing statistical methods, several reliability data types were formed. The data for the changes of words in the reading materials, the themes of the reading materials, and the designers' examination intentions were collected; all these are the validity information that were mainly focused on by former researchers.

Upon the collection of these latest data, comparisons were made with former information. This revealed of whether the suggestions by previous researchers were being adopted. Thereafter, the future development trend of the exam is discussed and suggestions for teachers as well as candidates' preparation of the exam are provided.

\section{Reliability and validity data of the reading part in TEM-8}

\subsection{Reliability analysis of the reading part in TEM-8}

According to scholars, the reliability of an exam comprises of several parts: whether the exam has a sample group that is large enough; the distribution of different types of questions or the time given for candidates; the design of the examination paper and the selection of reading materials ${ }^{[4]}$.

As a unified examination for all Chinese senior English majors, the sample size is large enough. As one of the tests in the series of examination for English majors, TEM-8 requires the candidates to complete each section in a given time, where rules have been implemented to see to it: students are only allowed 45 minutes to complete the reading part as their answer sheets for that part would be collected by the invigilator after that. TEM-8 is well-designed so that the quality of the test paper would not result in any negative influence on the candidates. Last but not least, the reading materials are selected from authoritative English magazines, newspapers, and other similar sources. In the 2021 exam, a section of The Heart Is a Lonely Hunter was included as one of the four reading sections. A certain degree of in-depth thinking is required to comprehend such a work; therefore, it would be challenging for candidates if they desire to obtain excellent grades in this examination.

From all these, it can be concluded that the reading part in TEM-8 is a reliable one.

\subsection{Validity data of the reading part in TEM-8}

The reading part in TEM-8 is formed by three or four individual sections. In view of the validity of the exam, although several researchers had collected data by using computer software, such as Wordsmith and so on, in a creative manner ${ }^{[5]}$, major researchers only focused on certain types of data, including the length of the reading materials (each section), their themes and styles, as well as the word count ratio of the length of a chapter to the length of the questions.

With the directives mentioned above, data in various formats can be collected as shown in the latter part of this section. 
Table 1. Length of each reading material in TEM-8 (2016-2021)

\begin{tabular}{ccccccc}
\hline Year & $\begin{array}{c}\text { Section A } \\
\text { (words) }\end{array}$ & $\begin{array}{c}\text { Section B } \\
\text { (words) }\end{array}$ & $\begin{array}{c}\text { Section C } \\
\text { (words) }\end{array}$ & $\begin{array}{c}\text { Questions* } \\
\text { (words) }\end{array}$ & $\begin{array}{c}\text { Total words } \\
\text { (reading materials only) }\end{array}$ & Total words \\
\hline 2016 & 1010 & 1031 & 1003 & 534 & 3044 & 3578 \\
2017 & 850 & 1328 & 820 & 492 & 2998 & 3490 \\
2018 & 840 & 856 & 850 & 610 & 2546 & 3156 \\
2019 & 1004 & 966 & 908 & 582 & 2878 & 3460 \\
$2020^{* *}$ & - & - & - & - & - & - \\
2021 & Has not been & Has not been & Has not been & Has not been & Has not been & Has not been \\
& revealed yet & revealed yet & revealed yet & revealed yet & revealed yet & revealed yet \\
\hline
\end{tabular}

*There are two types of questions; namely, multiple choice ("Questions" here include the words which comprise the choices) and brief answers.

**Due to COVID-19, TEM-8 did not take place in 2020. Candidates (senior students of the year 2020) that were supposed to sit for the exam had to wait for the following year to be examined together with the senior students of the year 2021. During the time that this article was written, the test paper for 2021 was not classified yet; only fractions of information were being recalled by the candidates as recorded in the table below.

Table 2. Themes and styles of the reading part in TEM-8 (2016-2021)

\begin{tabular}{|c|c|c|c|}
\hline Year & Theme and style of section A & Theme and style of section B & Theme and style of section $C$ \\
\hline 2016 & $\begin{array}{l}\text { Looking for Gatsby; narration: } \\
\text { The Great Gatsby (excerpt) }\end{array}$ & $\begin{array}{c}\text { Introduction of "cyberspace" and its } \\
\text { threats; exposition }\end{array}$ & $\begin{array}{l}\text { Advice on raising the quality of } \\
\text { higher education; argumentation }\end{array}$ \\
\hline 2017 & Travel comments; exposition & $\begin{array}{c}\text { English teaching advice; } \\
\text { argumentation }\end{array}$ & $\begin{array}{c}\text { A passage from a writing textbook } \\
\text { (excerpt); narration }\end{array}$ \\
\hline 2018 & $\begin{array}{l}\text { Australia and its British } \\
\text { immigrants; exposition }\end{array}$ & $\begin{array}{l}\text { Languages and their rooted biasness; } \\
\text { argumentation }\end{array}$ & Sister Carrie (excerpt); narration \\
\hline 2019 & $\begin{array}{c}\text { Seize the Day (excerpt); } \\
\text { narration }\end{array}$ & $\begin{array}{c}\text { Contrastive study of two newspapers } \\
\text { and their owners; exposition }\end{array}$ & $\begin{array}{l}\text { Introduction of bandits on screen; } \\
\text { argumentation }\end{array}$ \\
\hline 2020 & - & - & - \\
\hline 2021 & Has not been revealed yet & $\begin{array}{l}\text { The Heart Is a Lonely Hunter } \\
\text { (excerpt); narration* }\end{array}$ & Has not been revealed yet \\
\hline
\end{tabular}

*Recalled by the candidates of the examination; its authenticity is yet to be confirmed.

\section{Comparison with data collected from former research}

By reviewing the data (reading part of TEM-8 in 2010 to 2015) collected by Liu, Yi, and other researchers ${ }^{[6-8]}$, several conclusions can be derived as follows:

Although the examination had reduced the number of individual sections in the reading part from four to three since 2016, which appears to be less stressful for candidates, the length of the individual sections and total words of the reading materials in each examination have increased. However, students are still required to solve all the questions within 45 minutes, thus raising the difficulty of completing the tasks.

A simplification can be seen in the aspect of the design of the questions. Reviewing the data offered by former researchers, the average number of words applied for questions is more than 600 words (2010 to 2015) with an extreme figure of 815 words in 2010. However, in all the examinations that took place between 2016 to 2021, other than in 2018, where the number of words applied for questions reached 610 words, all others had lower than 600 words. 
Several scholars suggested that more literary works which are closer to the lifestyle of the candidates ought to be selected as materials for the reading part. It seems that the idea has been accepted since the themes that have been selected in the reading part corresponded to the life and career paths of English majors, such as "teaching advice for English reading class," "immigrants and the problems they might face living far from home," and so on. In addition, it can be appreciated that the selection of styles for the different sections in each examination is more balanced. Between 2010 and 2015, there were six examinations with 24 reading sections, of which 10 of them were expositions. This reveals the inclination of the designers for a certain style. Since 2016, the reading part of each examination comprised of an equal number of excerpts of all writing styles; namely, one narration, one exposition, and one argumentation.

\section{Exam-preparation advice for both instructors and candidates}

The reading materials of the reading part in TEM-8 are selected from highly authoritative native English texts, which include academic works by linguistics and novels written by famous authors. Hence, it is not easy for students to acquire the meaning of the texts in addition to the limited time provided to complete all tasks; in other words, to pass the examination. Therefore, instructors need to help students to build up their comprehension competence by encouraging them to read extensively. This goal can be achieved through both curricular and extracurricular activities: adequate reading materials should be selected, students should be guided to read in senior English or extensive reading classes, and a list of books, including classic works with beautiful language and attractive plots which students would be interested in [9], should be recommended for after-class reading. As the materials for the reading part in the examination are often derived from journals, such as The Economist, Nature, etc., teachers should also guide students to read articles in these type of journals in order to cultivate their reading competence ${ }^{[10]}$.

As TEM-8 is an important criterion for reflecting the academic level of English majors and an important basis for employers to determine the skills of their applicants, exam candidates ought to work hard to pass the examination, or even better, to obtain excellent grades. For several scholars, this would mean that the candidates should put in effort to improve their basic skills; namely, listening, writing, translation, etc. ${ }^{[11]}$.

\section{Acknowledgements}

I would like to extend my gratitude to this journal, which provides a platform for researchers to share thoughts and ideas. The construction of this article was not possible without the knowledge and methodology developed by former researchers in this field.

\section{Disclosure statement}

The author declares that there is no conflict of interest.

\section{Author contributions}

Liqiao Liang, as the sole author of this article, undertook all work involved in this research, including material preparation, essay writing, revising, etc.

\section{References}

[1] Baidu.com, TEM-8. https://www.baidu.com/s?ie=utf-8\&f=8\&rsv_bp=1\&rsv_idx=1\&tn=49055317_4 _hao_pg\&wd=\%E4\%B8\%93\%E5\%85\%AB\&fenlei=256\&rsv_pq $=$ c58b108000038615\&rsv_t=aab 8 
2N6IeY3zbB7gDF1qy3ocJOAi6JRuWp9WZdbPzOZKDN\%2FGsmBhOEbB5cUUgcOKY0BFV2R POfE\&rqlang $=$ cn\&rsv_dl $=$ tb\&rsv_enter $=1 \&$ rsv_sug $3=9 \& r s v \_s u g 1=3 \& r s v \_s u g 7=101 \&$ rsv_sug $2=0$ \&rsv_btype $=i \& i n p u t T=1155 \& r s v \_s u g 4=4133$ (accessed on September 3, 2021).

[2] Baidubaike, 2017, TEM-8. https://baike.baidu.com/item/\%E8\%8B\%B1\%E8\%AF\%AD\%E4\%B 8\%93\%E4\%B8\%9A\%E5\%85\%AB\%E7\%BA\%A7\%E8\%80\%83\%E8\%AF\%95/6297184?fromtitle= $\% \mathrm{E} 4 \% \mathrm{~B} 8 \% 93 \% \mathrm{E} 5 \% 85 \% \mathrm{AB} \&$ fromid $=2224220 \& \mathrm{fr}=$ aladdin (accessed on September 3, 2021).

[3] Zhang YK, 2016, A Study of Reading Comprehension in TEM-8 between 2013 and 2015. Journal of Qiqihar University (Philosophy \& Social Science Edition), (11): 133-135, 138. 10.13971/j.cnki.cn231435/c.2016.11.040

[4] Liu KX, 2020, The Validity and Reliability of TEM-8 Exam. Overseas English, (05): 88-89.

[5] Hu P, Tai ZH, 2021, A Study on the Cognitive Diagnosis of Reading in TEM-8 Based on G-DINA Model. Modern Communication, (09): 82-84.

[6] Liu L, Yi SS, 2016, An Analysis of Content Validity in the Reading Part of TEM-8. Journal of Hubei University of Technology, (06): 93-95.

[7] Han X, 2014, On the Validity Research of the Year 2011 TEM-8 Exam (Reading Section). Journal of Hubei University of Science and Technology, (02): 124-125. 10.16751/j.cnki.hbkj.2014.02.055

[8] Chen HQ, 2011, Validity Analysis on TEM8 Reading Comprehension. Journal of Yancheng Institute of Technology (Social Science Edition), (03): 91-94.

[9] Li WY, Han X, 2012, The Backwash Effect of TEM8 on the Teaching and Learning of the English Major of Independent College. Overseas English, (16): 97-98.

[10] Li JX, 2019, Development of English Majors' Reading Ability of Foreign Journals. Think Tank Era, (52): 202-203.

[11] Wang S, Yang DL, Chen CL, 2010, An Exploration of Teaching to Improve the Performance of TEM8 Exam. Scientific and Technological Innovation, (08): 172. 